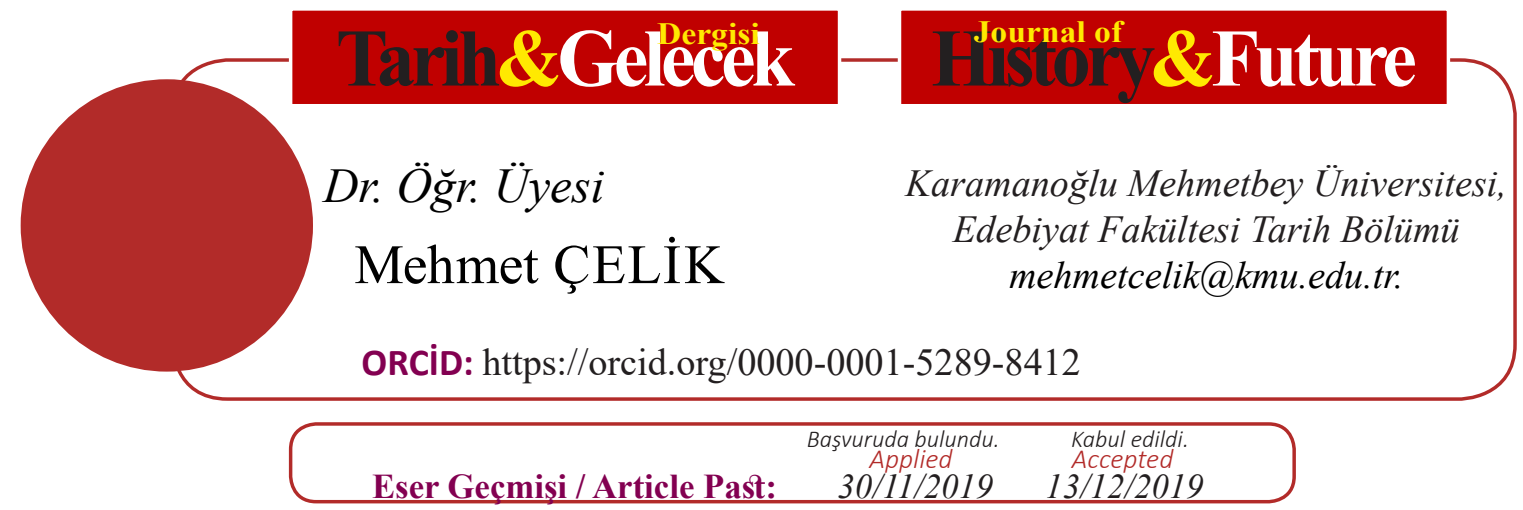

Araştırma Makalesi

DOI: http://dx.doi.org/10.21551/jhf.653426

Orjinal Makale / Orginal Paper

\title{
Tarihsel ve Demografik Bir Kritik: Lübnan'daki Kürtler
}

\author{
A Critical Historical and Demographic: Kurds in Lebanon
}

\section{$\ddot{O} \mathbf{z}$}

Lübnan'daki Kürtler, dil, kültür ve tarihi geçmişi bakımından farklılık göstermektedir. Dilleri ve kültürleri temelinde içtimai ve iktisadi anlamda bütünleşememiştir. Kürtlerin bu durumu, Lübnan sisteminin kurumsal yapısından ziyade aile kimliği, eski kabile ve geleneksel uygulamalarını sürdürmelerinden kaynaklanmıştır. Kürtlerin Lübnan'daki varlığına dair bilgiler sınırlıdır. Bu kısmi bilgiler ile Lübnan'daki Kürtlerin tarihsel varlı̆̆ına ve demografik yapısına dair sınırlı sayıda araştırma yapılmıştır. Lübnan'daki Kürtler üzerine yapılan tartışma, tahlil ve incelemeler bu sınırlı çalışmalar üzerinden yapılırken tahrifat da söz konusu olmuştur. Yapılan araştırmalar, Lübnan'a göç eden Türkiye Arapları olarak bilinen Mardinlileri de Kürtler olarak sınıflandırmaktadır. Aynı şekilde Lübnan'daki 'Nüfus Sayımı' sorunsalının devam ediyor olmasına rağmen yapılan araştırmalarda, demografik verileri tahmini çıkarımlara dayandırılmıştır. Bu makale, bu muğlak olguları açıklığa kavuşturmayı amaçlamaktadır. Araştırma, Tarih yazımı açısından tarihsel ve demografik kritiği temel alarak Lübnan'daki Kürtler üzerine kapsamlı bir araştırma olarak sunulmaktadır. Kürtlerin Lübnan toplumuna entegrasyon süreçlerini de tespit etmeyi amaçlayan makale, Lübnan'daki Kürtler üzerine sorulara cevap aramaya çalışacaktır. gruplar

Anahtar kelimeler: Lübnan'daki Etnik Yapı, Lübnan'daki Kürtler, Lübnan Demografisi, Kritik. Lübnan'daki

\section{Abstract}

The Kurds in Lebanon shows differ in terms of language, culture and historical background. They could not integrate socially and economically on the basis of their language and culture. This situation arises from the continuation of family identity, the old tribe and traditional practices, rather than the institutional structure of the Lebanese system. Information about the presence of Kurds in Lebanon is limited. With this partial information, a limited number of studies have been conducted on the historical existence and demographic structure of the Kurds in Lebanon. The studies, analyzes and investigations on the Kurds in Lebanon have also been falsified due to these limited studies. The research, known as Turkey Mardin Arabs, who immigrated to Turkey from Lebanon, has been classified as Kurds.Moreover, although the problem of 'Census' in Lebanon continues, demographic data are based on estimated inferences. This study aims to clarify these ambiguous cases.In the study, based on historical and demographic critique in terms of historiography It is presented as a comprehensive research on the Kurds in Lebanon. The study will try to find answers to the questions on the Kurds in Lebanon by identifying the integration process of Kurds into Lebanese society. Lebanon

Keywords: Ethnic Structure in Lebanon, Kurds in Lebanon, Demographics of Lebanon, Critical. Groups in

ATIF: ÇELIKK Mehmet, “Tarihsel ve Demografik Bir Kritik: Lübnan'daki Kürtler” Tarih ve

Gelecek Dergisi, 5/3 (Åralık-2019), s. (624-635)

CITE: ÇELIK Mehmet, "A Critical Historical and Demographic: Kurds in Lebanon" Journal of History and Future, 5/3 (December- 2019), pp. (624-635) 


\section{Giriş}

\section{Tarihsel Boyutuyla Lübnan'daki Kürtler}

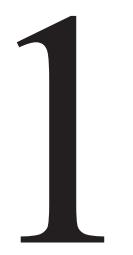

3. asır Lübnan jeopolitiğinde hâkim güç olan Memlûkler, Lübnan'daki Kürtlerin tarihsel sürecini dönemsel bir olgu olarak başlatmıştır. Memlûkler, iç bölgelerdeki hinterlandın kontrolünü sağlamak ve buradaki otoriteyi tesis etmek için Türk ve Kürtlerden müteşekkil kabile kolonileri kurmuştur. Özellikle Akkar, Trablus ve Beyrut'un güneydoğusundaki Shouf'(Şûf)ta birkaç Kürt feodal ve askeri yerleşim yeri olmuştur. Esasen bu feodal aileler, Araplaştırılmış ve dönemin Lübnan sosyolojisine entegre edilmiş kimselerdir. ${ }^{1}$ Bu itibarla Kürtler, Lübnan'da bir nevi paralı askeri kuvvet olarak dönemsel varlık göstermiştir. Lübnan'daki Kürtlerin tarihsel süreçteki varlığına dair Lübnanlı tarihçi Kemal Salibi'nin değerlendirmesi şu şekildedir:²

'Lübnan Dağı'nın eteklerinde, bir il idare merkezi olarak Tripoli, iç kısımdan kolayca erişilebilen bir kent olduğundan dezavantaja sahiptir. Akkār ve Buqay’a ovaları dışında, Tripoli’yi geleneksel olarak oluşturan bölge, çoğunlukla isyana eğilimli, katı Hıristiyanlar ve muhalif Müslümanlar (Nusayri veya Alevi) tarafından alışkanlık haline getirilmiş isyancılığa eğilimli olmuştur. Memlūkler zamanında, Tripoli, idaresi zor olan Alevi bölgesini kontrol etmek için en az dokuz büyük kale ile Akkār ve Buqay’a ovalarının iç geçişi sürdürdü; ilin daha problemli bölgeleri, özellikle Lübnan Dağı'ndaki Marunî bölgeler daha etkin bir şekilde kontrol edilmiyordu; Kahire'deki Memlūk makamları onlarla ilgili hiçbir şey bilmiyordu. Açıkçası, Tripoli'den geçişi kontrol altına almak için başından itibaren Müslüman devletler, Akkār ve Buqay’a ovalarının her iki yanında sadık Müslüman kabilelerin yerleşim yerlerini kurdular. Halep'in Mirdāsid prensi Sibl al-dawla Nasr (1029-1040), Alevi dağlarının güney ucunda bir Kürtler kolonisi kurduklarını söylemiştir. Kuzeyden Humus-Tripoli geçişine hâkim olan Ḥișn al-Akrād kalesi, onlardan sonra böyle anılmıştır. On ikinci yüzyılın ilk yıllarında Hiș̣n al-Akrād, Tripoli topraklarının geri kalanıyla birlikte Haçlı eline geçti ve her tür kabile yerleşiminin görünüşte dağınık ya da bastırılmıştı. Ancak 13. yüzyılın sonlarında Memlūkler Suriye kıyılarını Haçlılardan geri aldı ve dağ sırtını kontrol etmek ve iç bölgeleri korumak için Lübnan'ın çeşitli bölgelerinde ve başka yerlerde Kürt ve Türkmen kabilelerden yeni koloniler kuruldu."

Kemal Salibi'nin temas ettiği Hiṣn al-Akrād kalesinin bulunduğu yer vilayet salnamelerinde; Trablusşam merkezi kazasının kuzey doğu cihetinde bulunan, kuzey doğusunda Humus ve güneyinde Akār, batısında Sâfitâ kazalarıyla hudut olmuştur. Hiṣn al-Akrād kalesi "Ehli salib muharabeleri"’3 zamanında Krak des Chevaliers namıla maruf olmuştur. ${ }^{4}$ Arap müverrihlerin verdiği

1 Ismet Chériff Vanly," The Kurds in Syria and Lebanon", The Kurds A Contemporary Overview, (Ed. Philip G. Kreyenbroek and Stefan Sperl), Routledge, London 1992, s.129; KDP'nin Avrupa'daki temsilcisi olan Ismet Chériff Vanly için ayrıca bkz. Clémence Scalbert-Yücel and Marie Le Ray, "Knowledge, ideology and power. Deconstructing Kurdish Studies", European Journal of Turkish Studies [Online], 5/2006, URL: http://journals.openedition.org/ejts/777.

2 Kamal S. Salibi, "The Sayfās and the eyalet of Tripoli 1579-1640”, Arabica, T. 20, Fasc. 1, Feb. 1973, s.28.

3 XI. yüzyılın sonlarında Avrupa dünyasının "Kudüs'ü kurtarma” sloganı ile, Türkler’i Anadolu'dan atmak ve bütün Ortadoğu'yu ele geçirmek için başlattığı siyasî amaçlı askerî harekâta katılanlara verilen ad. Dönemin Müslüman tarihçilerinin "Franklar" kelimesiyle ifade ettiği Haçlılar tabiri, Doğu'da ilk defa Osmanlılar tarafından Fransızca "Croisades" kelimesinin karşılığı olarak "ehl-i salib", Araplar tarafından da "Salîbiyyûn" şeklinde kullanılmaya başlanmıştır. Ayrıca Bkz. Demirkent, Işın, "Haçlılar", TDV İslâm Ansiklopedisi, c.14, 1996, ss. 525.

4 Kazanın doğusu, kuzeyi ve güney tarafları dağlık, kalan kısmı ova halindedir. En yüksek noktası teşkil eden cebel el sabah 550 metre irtifaındadır. Kaza dahilinde bulunan nebi el nasriye, nebi fırayşlu(?), 
malumatlara göre; 424 Sene-i Hicriyesinde humus valisi Sibl al-dawla Nasr bin Miradis kaleye müdafaa vazifesiyle mükellef olmak üzere Kürtlerden bir firka askeriye izam etmekle istihkam olunmuştur. Bir zamanlar kale, "Hișn al-Safh" namıla maruf olmuştur. Bu kazâda Türkmen, Nusayri ve Hristiyan nüfus bulunmuştur. ${ }^{5}$ Yine Yâkūt el-Hamevî'nin Mu 'cemü'l-büldân ${ }^{6}$ adlı eserinde de Hịṣn al-Akrād'ın coğrafi konumunu sarp bir yer olarak tasvir edip tafsilatlı bilgi verirken buradaki Kürtleri, Şam Emirleri Franklere karşı paralı öncü bir kuvvet olarak kullanmış, daha sonra kalenin güçlendirilmesine rağmen Kürtlerin, burasını satıp terk ettiklerini yazmıştır. ${ }^{7}$ 17. yüzyılın başlarında Tripoli, Hișn al-Akrād ${ }^{8}$ ve Kūra bölgesi, Yusuf Paşa'nın (Yûsuf b. Sîfe) kontrolü altında Âl Sîfe (Seyifoğulları-Sayfās) ${ }^{9}$ ailesine sadık Osmanlı birlikleri ile Lübnan'a gelen Rās Nhās' aşireti mensubu Kürt emirleri tarafindan korunmuştur. ${ }^{10}$ Esasında Lübnan'daki Kürtleri, Eyyubiler döneminde göç edip Araplaşanlar, Osmanlı Devleti döneminde gelenler ve Türkiye Cumhuriyeti'nin kurulmasından sonra özellikle Mardin ve Haseke'den göç edenler olarak ayırmak mümkündür. Şöyle ki; Kürtlerin ilk olarak Baalbek çevresine yerleștiği iddia edilmiştir. Ayubi, Orfali, Doughan, Kurdi, Kalash gibi Kürt aileler, Türkiye'den Osmanlı birlikleri ile gelmiştir. ${ }^{11}$ Ancak Lübnan'daki bugünkü Kürtler, Araplaşmış Kürtlerden ziyade esasen Mardin' den gelen Türk Arapları ile Cizre'den gelen 1920'li ve 1930'lı yıllarda Beyrut'a yerleşen eski şarap üreticileri ve köylülerden oluşmuştur. ${ }^{12}$ Dolayısıyla 20. yüzyılın ilk yarısında Lübnan'a gelen Kürtlerin çoğu,

nebi ayn fıraş çayları ...1329 senesinden beri Kar yağdığı görülmemiştir. Yazın sıcaklık 32 ye kadar çıkar, kışın 7-8 derecedir. Kaza merkezi olan takalı̆̆(?) kasabasından takriben iki saat ba’dende ve bakıme ovasının kenarında vakaa olan... Beyrut Vilâyet Salnâmesi Şimal Kısmı, H. 1333-1336 (M. 1914-1915/1917-1918). s.356-357.

5 Beyrut Vilâyet Salnâmesi Şimal Kısm1, H. 1333-1336 (M. 1914-1915/1917-1918). s.356-357.

6 Yâkūt, 615 (1218) yılında Merv'de bulunduğu sırada, hocası Abdürrahîm b. Abdülkerîm es-Sem‘ânî’nin hadis dersinde Arap yarımadasında düzenlenen panayırlardan birine adını veren Hubâşe'nin okunuşu hususunda çıkan bir tartışma üzerine yer adlarıyla ilgili bir esere ihtiyaç duyulduğunu farkedip eserini yazmaya karar verdiğini söyler. Ayrıca bkz. Casim Avcı, Avcı, Casim, "Yâkūt El-Hamevî", TDV İslâm Ansiklopedisi, c.43, (2013), s.288.

7 Yâkūt el-Hamevî, Mu'cemü'l-büldân, Dâru's Sadr, Beyrut, s.264.

8 Hiṣn al-Akrād ("Kürtlerin Kalesi”), Arapça; Qal'at al-Hụṣn (al-Ḥiṣn, modern Arapça; “Kale”), Ḥiṣn al-Firās (al-Fursān, "Şövalyelerin Kalesi"), Suriye'de Haçlı döneminde (488-690/1095-1291) inşa edilen ve Memlūk saltanatı (648-953/1250-1517) döneminde de çok sayıda ilâve yapılan bir kaledir. Milwright, Marcus, "Hișn al-Akrād", Encyclopaedia of Islam, Three, Edited by: Kate Fleet, Gudrun Krämer, Denis Matringe, John Nawas, Everett Rowson.; Halep'in Mirdāsid prensi Sibl al-dawla Nasr, burada 422/1031 tarihinde bir Kürt askeri kolonisine yerleşerek yolların Ḥumuṣ ve Ḥamā’dan Tripoli’ye doğru batıdan gelen saldırılara karşı korunması için tarlaları onlara vermişti. Kürtlerin gelişiyle bu bölge, Ḥișn al-Akrād olarak bilinir hale geldi. Elisséeff, N., "Hiiṣn al-Akrād", Encyclopaedia of Islam, Second Edition, Editedby: S. Bearman, Th. Bianquis, C.E. Bosworth, E. vanDonzel, W.S. Heinrichs.

9 Âl Sîfe (Seyifoğulları) ailesi Maraş Türkmenleri’ndendi ve bu aileden Yûsuf b. Sîfe (Seyfoğlu Yûsuf Paşa) öne çıkmıştı. Yûsuf Paşa bölgede uzun süre valilik yaptı. Ayrıca bkz. Bayat, Fazıll, "Trablusşam Eyaleti", TDV İslâm Ansiklopedisi, c.41, (2012), s.295.

10 Kamal S. Salibi, "The Sayfās and the eyalet of Tripoli 1579-1640", Arabica, T. 20, Fasc. 1, Feb. 1973, s.48.

11 Najlaa Aboumerhi, "Kurds in Lebanon", https://www.beirutobserver.com/2012/03/kurds-in-lebanon-najlaa-aboumerhi/, (E.T.08.03.2019).

12 Ismet Chériff Vanly," The Kurds in Syria and Lebanon", s.129. 
Suriye yoluyla Mardin, Midyat ve çevresinden (Turabdin ${ }^{13}$ ) Türkiye'deki 1925 Şeyh Said İsyan1 ${ }^{14}$ ile gelirken 1950'li yılların sonlarında ve 1960'lı yılların başlarında ise Suriye'den gelenler oluşturmuştur. ${ }^{15}$ Ayrıca 1958-1961 yılları arasında kurulan Mısır-Suriye ittifakı, Suriye' deki birçok Kürt'ün Lübnan'a göç etmesine neden olmuştur. Suriye'deki Kürtlerin göçünü takiben Irak'tan bir başka grup da Lübnan’a göçü başlatırken Irak’taki 1958 darbesine müteakip yaşanan olaylar, 1961-1975 yılları arasında Lübnan'a Kürt göçünü de arttırmıştır. ${ }^{16}$ Dolayısıyla 1925 yılı ile 1930'lu yıllarda Mardin ve çevresinden, 1950 ve 1960'l1 yıllarda Suriye'nin kuzeyindeki Haseke'den ve 1958-1975 yılları arasında Irak’tan Kürtlerin Lübnan'a ulaştığı tahmin edilmektedir. ${ }^{17}$

\section{Demografik Bağlamda Lübnan'daki Kürtler}

Lübnan'da '1932 Nüfus Sayımı' sonrası resmi bir nüfus sayımının yapılmamasından dolayı Lübnan'daki Kürt nüfusu ile ilgili veriler de yoruma dayanmaktadır. ${ }^{18}$ Lübnan'daki Kürtler ile ilgili araştırma yapan G. Hourani’ye göre: Beyrut'taki Kürt nüfusu; 1927'de 300, 1936'da 1500, 1944 'te ise 7000'e yükselmiştir. 1927-1936 yılları arasında Kürt nüfusundaki bu artışın en önemli nedeni Beyrut'un ekonomisi olmuştur. 1950'li ve 1960'lı yıllardaki inşaat sektörünün büyümesi ile ekonomik durumu iyileşen Kürtler, Türkiye ve Suriye'de yaşayan Kürtlere finans sağlayarak Lübnan'a Kürt göçünü teşvik etmiştir. ${ }^{19}$ Lübnan'daki KDP'nin kurucusu Jamil Mihhu, 1975'te Lübnan'daki Kürt nüfusunun 70.000 olduğunu dile getirirken 1977'de yayınlanan “Kürt Sorunu İçin Yeni Bir Vizyon" adlı broşüründe; 75 ila 100 bin arasında olduklarını iddia etmiştir. Lübnan gazetesi ElAnwar, 8 Mayıs 1991 tarihli haberinde Kürt nüfusunu 35 bin olarak, An-Nahar ise 2 Ekim 1993 tarihli haberinde Lübnan'daki iç savaş sonrası Kürt nüfusunun 15 bin düştügüne yer vermiştir. Birleşmiş Milletler Mülteciler Yüksek Komiserliği 2008 yılı tarihli raporunda Lübnan'daki Kürt nüfusunu 25.000 veya toplam Lübnan nüfusunun \%0,6's1 olarak tespit edilmiştir. ${ }^{20}$ Beyrut İngiliz

13 Turabdin, batıda Mardin, kuzeyde Hasankeyf, doğuda Cizre ve güneyde Nusaybin kentlerinin çevrelediği ve merkez kenti Midyat olan bölgedir. Yakup Bilge, “Turabdin: Süryani Kilise ve Kültürünün Beşiği”, Uluslararası Midyat Sempozyumu, 1-9 Ekim 2011 Mardin, s.509.

14 Şeyh Said İsyanı ve devamında ilan edilen Takrir-i Sükûn Kanunu ile ilgili bkz. Mehmet Özalper, "Bir Muhalefet Partisinin İlgası: Terakkiperver Cumhuriyet Fırkası", Anemon Muş Alparslan Üniversitesi Sosyal Bilimler Dergisi, C.2, s.1.

15 Jason Tucker, Challenging the tyranny of citizenship: statelessness in Lebanon, (Unpublished phd thesis), University of Bath, Sept. 2013, s.39; Guita G. Hourani, The Kurds of Lebanon: Socioeconomic Mobility and Political Participation via Naturalization, The Lebanese Emigration Research Center (LERC) Notre Dame University-Louaizé (NDU), Lebanon, November 2011, s.25.

16 Jason Tucker, age, s.40.

17 Guita G. Hourani, age, s.29; Kayıp Kürt kolonileri: Misır, Ürdün, Lübnan, Filistin ve Yemen Kürtleri, http://www.bitlisname.com/2018/07/30/kayip-kurt-kolonileri-misir-urdun-lubnan-filistin-ve-yemen-kurtleri/, (E.T.30.07.2018).

181932 nüfus sayımı, Lübnan devletinin inşası sürecinde önemli bir rol oynamıştır; 1932 nüfus sayımına göre, Lübnan'daki Hristiyan “çoğunluğun” daha politik olduğunu, "Lübnan topraklarında önemli bir nüfusun dışlanmasına ve göçmenlerin tartışmalı bir şekilde dahil edilmesine” dayandığını göstermiştir. 8837 Sayılı Kararnamede yapılan nüfus sayımı ilkeleri, Lübnan vatandaşlığı için Müslüman başvuranlardan ziyade Hristiyanlığın vatandaşlığa geçmesini desteklemiştir. Najlaa Aboumerhi, "Kurds in Lebanon",https:/www.beirutobserver.com/2012/03/kurds-in-lebanon-najlaa-aboumerhi/, , (E.T.08.03. 2019).

19 Guita G. Hourani, s.29.

20 Minority Rights Group International, World Directory of Minorities and Indigenous Peoples- Lebanon, June 2008. https://www.refworld.org/docid/4954ce52c.html. (E.T. 13.07.2019); Lübnan İç Savaş1, 1982'de İsrail'in Lübnan’1 işgali ve en önemlisi de Şiiler ile Sünniler arasında Kürtleri de içeren çatışmalar, Kürt göçüne neden olmuştur. Ayrıca Suriye’nin Lübnan'da kontrol ettiği bölgelerdeki terör ör- 
konsolosluk raporlarında ise KDP'li Abdül Karim ile yapılan bir görüşmede Kürt nüfusu ile ilgili şu bilgiler öne çıkmıştır. ${ }^{21}$

“Abdülkerim, 1975-76 olaylarından önce Lübnan'da 70-80 bin Kürt'ün olduğunu söyledi. Bu sayl artık göç nedeniyle 50.000'e düşü̈. Bunlardan 10,000'i Lübnan vatandaşliğl elde etmiş ve diğerlerinin Lübnan vatandaşlığına yönelik başvurularl "incelenmiştir". Beyrut'taki Kürtlerin çoğu Bab Idriss, Kantari, Zarif, Zuqaq al Blat ve Wadi Abu Jamil bölgelerinde yer alırken 1976 yllinda Karantina ve Tel el Zaatar'dan St Simeon Ouzai bölgesinde de olmuşlardl". "Abdül Karim, Damour'a giden Kürtlerin saylsının önemsiz olduğunu düşünürken, Ouzai'deki sahil şeridinde bulunan Kürtlerin, mali kaynaklara sahip olmayan Lübnanlv ve Filistinli solcu grupların ellerinde olduğunu gözlemlediler. Kürt mültecilere yardım eden Lübnan devleti, genel olarak, Lübnan'daki Kürtlerin, devletin baskısının yokluğundan fayda gördüklerine, aşırılık yanlısı olduklarını itiraf etti."

Lübnan'daki Kürtler hakkındaki demografik bilgiler çeşitli tahminlere dayanırken Kürt nüfusunun en abartılı tahmini, siyasi partilerin ve siyasi seçkinlerin kâr amaçlı pazarlıkları sonucu ortaya çıkmıştır. Örneğin David Mc Dowall22, "Modern Kürt Tarihî" adlı eserinde göçler sonucu Lübnan'da en az 100.000 Kürt nüfusu olduğunu belirtirken bu bilgiyi de Lokman İbrahim Meho'nun The Case of The Kurds In Lebanon," adlı Yüksek Lisans tezine dayandırdığını belirtmiştir. Yazarın temas ettiği istatistiksel veri adı geçen tezde; "Lübnan'da tahmini olarak 1985 'lere kadar 40 ila 100 bin arasında" bir sayının olduğunu verirken tezin yazıldığı yıla (Aralık 1995) atıf yaparak; "ancak şu an 40 binden fazla bir sayı" olarak verilmiştir. ${ }^{23}$ Dolayısıyla yukarıdaki tez kaynak gösterilerek verilen bilginin "tahmini olarak" verilmesine ve bahse konu olan tarihte de 40.000 olarak verilmesine rağmen David Mc Dowall, bilgiyi tahrif etmiştir.

Lübnan'daki Kürtlerin çoğu, Mardin, Midyat ve çevresindeki “ $\ddot{U}$ ķavak (Rajdiye), Yenilmez (el-Mkhashniyeh), Kayatepe (el-Mnezil), Söğ̈̈tlü (Kinderib), Ömerli (Ma'sarteh-Mahsarte), Marjeh, Jib al-Graw, Marska, Zeni, Fateh, Matina" köylerinden gelmiştir. ${ }^{24}$ Lübnan'daki Kürtler, Kabile ve dilsel farklılık dışında inanç bağlamında Sünni mezhebinin fikıh mezhebi olan şafidirler. Kürtler, aşiretlere, geldikleri köy ve bölgeye bağl1 olarak birçok gruba bölünmüştür. Bu ortak gruplar, el-Rajdiyeh, Ma'sarteh, el-Mkhashniyeh, el-Mnezil, Marjeh, Jlb al-Graw, Kinderıb, Marska, Zem, Fateh, Matina vs gibi kökenleri ile adlandırılmışlardır ${ }^{25}$. Burada çok önemli bir hususu belirtmekte yarar var; Lübnan'daki Mardinliler, "Kürt veya Arap Kürtleri”" olarak tanımlanmayı ve sinıflandırılmayı reddederken Mardin'de yaşayan atalarını 'Türk Arapları' olarak adlandırmayı tercih etmektedirler. Kasravani, Mardinlilerin bir teşekkülü olan Gelecek Nesil (Jil al Mustaqbal) Derneği'nin başkanı ile görüşmesinde; "Kürt meselesiyle hiçbir ilgilerinin olmadığı, sempati duymadıklarını ve Türkiye'deki Kürt militanlığı konusunu tartışmayı reddettiklerini belirtmiştir. Bu derneğin yöneticileri ayrıca Türkiye'deki köylerdeki akrabalarının barış içinde yaşadıklarını ve PKK terör örgütü ile Türk ordusu arasındaki çatışmaya katılmadıklarını" vurgulamıştır. Aynı tutumlarını Barzani ile ilgili olarak da ifade etmektedirler. Dernek, bir bütün olarak kendilerini hem

gütü PKK’nın kamplarına olan desteğinin geri çekmesi sonucu Lübnan'daki Kürt nüfusu azalmıştır. Bu göçlerin çoğunluğu da Almanya ve İsveç’e yönelmiştir. Guita G. Hourani, age, s.33.

21 FCO, 93/1999.

22 David Mcdowall, A Modern History of The Kurds, I.B. Tauris, New York 2007, s.485.

23 Lokman İbrahim Meho, agt, 46.

24 Guita G. Hourani, age., s.33; Köylerin isimleri hakkında ayrıca bkz. Bahaeddin Budak, Mahallemi Lehçesi, http://www.mahallemi.net/2012-07-19-10-49-29/187-bahaeddinbudak.html. 
“Arap Kürtleri” hem de Kurmancî Kürtlerinden ayırmaktadır. ${ }^{26}$

Kürtleri Lübnan'a göç etmeye iten en büyük nedenlerden biri de yukarıda vurgulandıği gibi Lübnan'ın iktisadi durumunun özellikle bankacılık sektörünün ivme kazanması olmuştur. 1976 yılına kadar Lübnan, Ortadoğu'nun ticaret ve finans merkezi olurken Batı ile Arap Dünyası arasındaki bağlantıyı kurması açısından da önemli bir hareket noktası haline gelmişti. Lübnan'ın ekonomik başarısı komşu ülkelerden çok sayıda işsizin uğrak yeri olmasını sağlamıştır ${ }^{27}$. Bu özelliği sebebiyle buraya göç eden Kürtlerin çoğunluğu Beyrut'ta sebze pazarlarında beden işçisi ve kutu üreticisi, daha sonra ise kademeli olarak tekelleşmiş bir sektör olan meyve sebze tüccarları olmuşlardır. Göç eden Kürt kökenli $\operatorname{Kadınlar}^{28}$ ise çoğunlukla temizlikçi ve kapıcı olarak çalışırken 1940'lardan itibaren genelde ev işlerini sürdürmüşlerdir. ${ }^{29} \mathrm{Kürtler,} \mathrm{zaman} \mathrm{içinde} \mathrm{inşaat,} \mathrm{oto-meka-}$ nik işçiliği, terzi ve marangozluk gibi pazarlanabilir beceriler kazanmışlardı. Kürtlerin bir bölümü kıyı şeritlerindeki meyve ve pazar bahçesi arazilerinde ve perakende pazarında seyyar satıcıları olarak, diğerleri ise "sosyal ve ekonomik ölçeğin en alt ucu, hamal, küçük esnaf ya da vasıfsız işçi olarak çalışmışlardır. 1950'li ve 1960'lı yıllarda inşaat sektörünün ivme kazanmasından faydalanan Kürtler, inşaat endüstrisinde günlük işçiler olarak çalışmışlardı. ${ }^{30}$ Yakın dönemde Lübnan'a göç eden Kürtler, genel olarak kenar semtlerdeki gecekondu bölgelerine yerleşmişlerdi. 1950'li 1960'lı yıllarda inşaatlarda çalışıp sınırlı bir yaşam standardına sahip olan Kürtlerden bir kısmı da işportacılık yapmıştır ${ }^{31}$.

Kürtler, Beyrut'taki düşük gelirli bölgeler olan al-Basta, Zqaq al-Blat, aşağı şehir bölgesi, Fum el-Şubbak, 'Ayn el-Mrayseh, Raml al-Zarif, Burj al-Brajneh, Burj Hammud, vb. yerlere yerleşirken diğerleri ve özellikle Suriye' den gelenler, El-Karantina-El-Maslakh gecekondularına yerleşmişlerdi. Beyrut dışına yerleşenler ise Trablus, Sidon, Tire ve Ba'albek arasında dağılmışlardır. ${ }^{32}$ Trablus ve Sidon gibi sahil kentlerine ve Biqa vadisindeki bir iç şehir olan Ba'albek'e yerleşen Kürtler ise sosyal ve ekonomik şartlar bakımından daha iyi bir seviyede olmuştur. ${ }^{33}$ Lübnan'daki Yahudi cemaatinin büyük bir kısmının göç ettiği yıl olan 1967'de, Bab idriss Mina'l-Hüsn ve Wadi Ebu-Jmil bölgeleri 1984'e kadar orada kalan yüzlerce Kürt aileyi almaya başlamıştır. 1976'nın başlarında El-Karantina-el-Maslakh gecekondularının yok edilmesinden sonra, hayatta kalanların çoğu Batı Beyrut, Haldeh ve El-Jnah'a ve yeni gecekonduların kurulduğu bölgelere taşınmıştır. 1982 yılının haziran ayında İsrail'in Lübnan işgali sırasında, birkaç bin Kürt Bekaa bölgesine yer-

26 Farah Wajih Kawtharani, s.84

27 FCO., 93/2421.

28 150'den fazla kadın işçiler ile yapılan yapılan bir araştırmada: 1975'te iç savaşın başlamasına kadar genellikle Lübnanlı kadınlar hizmetçi olarak kullanılır. 1990'a kadar 77'si Lübnanlı, 1962'ye kadar 24 Suriyeli, 1975'e kadar 22 Filistinli ve 18 Misırlı ve 1987'de biri olmak üzere ile 1970'lerin sonlarına doğru8 Kürt, 1990'dan sonra Sri Lanka, Filipinler ve Etiyopya'dan gelen kadınlar baskındı. Ayrıca bkz. Ray Jureidini, "In the Shadows of Family Life: Toward a History of Domestic Service in Lebanon “Journal of Middle East Women's Studies, Vol. 5, No. 3, War and Transnational Arab Families (Fall 2009), s.80.

29 Ray Jureidini, agm., s.76.

30 Guita G. Hourani, age, s.32.

31 Kayıp Kürt kolonileri: Misır, Ürdün, Lübnan, Filistin ve Yemen Kürtleri, http://www. bitlisname.com/2018/07/30/ kayip-kurt-kolonileri-misir-urdun-lubnan-filistin-ve-yemen-kurtleri/, (E.T.30.07.2018).

32 Lokman İbrahim Meho, agt,s.46.

33 Kayıp Kürt kolonileri: Mısır, Ürdün, Lübnan, Filistin ve Yemen Kürtleri, http://www. bitlisname. com/2018/07/30/ kayip-kurt-kolonileri-misir-urdun-lubnan-filistin-ve-yemen-kurtleri/, Erişim Tarihi: 30.07.2018. 
leşmiştir. $^{34}$

Kürtlerin büyük çoğunluğu Sünni olmakla birlikte Kuzey Kurmanji lehçesi konuşanlar ile Mardin'den gelen Türkçe, Arapça, Kürtçe ve Süryanicenin bir karışımı olan Mardin lehçesi konuşan Türk Arapları olarak ayrılmıştır. Türk Arapları, Lübnan hükümeti tarafından tanınan Mardinliler/ Muhallamiler ${ }^{35}$ 'dir. Lübnan Muhallamileri, "Atrisler, Fakhro, Fattah, Harb, Miri, Omari, Omayrat, Ramazan, Rammu, Şabu, Şerif, Şeyhmus, Siyala ve el-Zein gibi ailelerden oluşmaktadır. ${ }^{36}$ Kürtler, Lübnan'da mezhep sistemi içerisinde Sünni Müslüman kimliği altına alınmıştır. \%85'inin yoksulluk sınırında veya altında yaşadığını ve okuryazarlık oranlarının sadece \%40 olduğu ortaya çıkmıştır. Kürtler, Lübnan toplumunun sosyal katmanları konusunda düşük, çoğunlukla gayri resmi, sosyal işlerle uğraşmaktadır. Dolayısıyla Kürtler, Lübnan sosyolojisinde de önemli bir etki alanına sahip olmamıştır. ${ }^{37}$ Beyrut bölgesindeki Kürt ve diğer göçmenler, hizmet sektörünün büyümesine katkıda bulunan burjuva ailelerin ticari büyümesine de neden olmuşlardır. ${ }^{38}$ Kürtler, iyi bir servete ve eğitime sahip olmadıklarından sosyal sınıf olarak alt tabakaya mensup olmuştur. Şöyle ki; Kürtler, kökenleri itibariyle köylerinde muhafazakâr bir hayat yaşıyor. Köylülerin çoğu okuma yazma bilmediği ve dış dünyayla çok az etkileşime girdiği için eğitim neredeyse tamamen sözlü iletişime bağımlı olmuştur. Lübnan'a gelmeden önce yaşamlarının merkezi aile kimliği veya birey açısından bir araç olarak kullanılan köydü. Dağılımlarına rağmen, aşiretçilik, intikam, sözlü eğitim, aynı aile içinde evlilik ve büyüklere saygı gibi eski kabile veya kırsal uygulamalarının varlığını devam ettirmiştir. ${ }^{39}$

Lübnan'da iç savaşın yaşandığı yıllarda Lübnan'dan ayrılan Kürtlerin çoğu, ülkeyi düzenli olarak ziyaret etmeye devam etmektedir. Lübnan vatandaşlığı almış Kürtler, sosyo-ekonomik durumlarını 1994 yılı sonrasında iyileştirmiştir. Vatandaşlık alan Kürtlerin yarısından fazlası Lübnan doğumlu olduğundan Lübnan sistemine entegre olmuşlardır. Nüfus olarak Beyrut’ta toplandıkları için, kentte meydana gelen ekonomik imkanlardan da yararlanmışlardır. Beyrut'ta vatandaşlığa geçmek, Beyrut Sünni siyasal çevresi içerisinde Beyrut seçmeni olarak bir değer anlamına geldiğinden Kürtler açısından da önemli bir statü kazandırmıştır. ${ }^{40}$ Esasında 1925 yılında Lübnan vatan-

34 Lübnan’a göç eden Suriye Kürtleri ise 20. yüzyılın başında homojen bir grubu oluşturmazken aksine bölünmüş doğasıyla karakterize edilmiştir. Lokman İbrahim Meho, agt., s.47.

35 Muhallemi diye adlandırılan ve halen Tur Dă̆ı'nın güneyinde Turabdin (Midyat ve çevre köyleri) diye isimlendirilen mıntıkada varlıklarını sürdüren Araplar, Muhallem bin Zuhel bin Şeyban 'a bağlı olan bir aşirete dayandırılırlar. Ayrıca bkz. Ahmet Abdülhadioğlu, "Kadim Arap Kültürünün Midyat Halkının Gündelik Yaşamına Yansımaları", Uluslararası Midyat Sempozyumu (7 -9 Ekim 2011), s.790.ss 789803.; Mahallemiler, kendilerinin de kabul ettiği gibi Arap kökenli bir yapıya sahiptirler ki, Arapların bu coğrafyadaki varlığının en az miladi V. yüzyıla kadar gittiği bilinmektedir. Bu noktada Mahallemi/ Mhellemiyye isminin menşei önem kazanmaktadır. Bu isim Osman'ın da işaret ettiği gibi tarihi süreçte bu coğrafyada etkili ve nüfuzlu bir şekilde varlık göstermiş olan bir Arap kabilesine işaret etmektedir. Ayrıca bkz. Halit Yeşilmen, "Etno-Dini Kimlik Açıdan Mahallemiler", Artuklu Akademi, 2016/3 (2), 1-40. s.14.

36 Bu lehçeler o bölgede konuşulan en eski Arapça seviyesidir”. Guita G. Hourani, age, s.27-28.

37 Jason Tucker, Challenging the tyranny of citizenship: statelessness in Lebanon, s.41-42.

38 Guita G. Hourani, age, s.27-28.

39 Lokman İbrahim Meho, agt., s.48.

40 Najlaa Aboumerhi, “Lübnan'daki Kürtler”,https://www.beirutobserver.com/2012/03/kurds-in-lebanon-najlaa-aboumerhi/, (E.T.08.03.2019); Son olarak Lübnan'da Kürtlerle yapılan görüşmelerde Kürtlerin; "Lübnan'dan ayrılmak için bir planı olmasa da Lübnanlı hissetmiyorum" demektedir. Brooke Anderson, Kurds endure poverty, grapple with assimilation, The Daily Star, Feb. 09, 2012, http://www.dailystar.com.lb/News/Local-News/2012/Feb-09/162690-kurds-endure-poverty-grapplewith-assimilation.ashx\#axzz1lrOIfEZD, (E.T.18.07.2019) 
daşlığının tanımı genişletilerek vatandaşlığa geçme yasası getirilmişti. 1939 yılına kadar Lübnan vatandaşlığı veya vatandaşlığı, başvuru sahibinin en az beş yıl Lübnan'da ikamet etmesi veya bir Lübnanlı bir kadın ile evlendikten sonraki bir yıl boyunca ülkede ikamet etmesi şartıyla kararname ile verilmiştir (15 / S sayılı kararname 19 Ocak 1925). 1939'da bu yasa 19 Haziran 1939 tarihli 122 / LR sayılı Kararname ile feshedilmiş ve yerine Lübnan vatandaşlığına ancak on yıllık sürekli ikamet edildikten sonra verilebilecek olan 27 Mayıs 1939 tarihli hükümler eklenmiştir. Ancak, ertesi yıl, bu hükümler 30 Mayıs 1940 tarih ve 48 / LE sayılı Kanun Hükmünde Kararname ile iptal edilerek vatandaşlığa geçme, teorik olarak İmkânsız hale gelmiştir. Bununla birlikte, bazı durumlarda vatandaşlığa geçme, 1925'te geçerliliğini yitirmesine rağmen, 1925 Kararnamesi temelinde verilmeye devam etmiștir. ${ }^{41} 1$ Şubat 1956 'da Junieh'deki bir mahkeme, 13 Kürt ve ailesinin dini kimliklerini Maruni olarak değiştirdi. Bu kişilere 1956'da Rashid Karami döneminde Lübnan vatandaşlığ1 verildi. Buradan hareketle bir grup Keldani Hristiyan'a da vatandaşlık verilmesi konusu gündeme geldiğinde bir kriz ortaya çıktı. Lübnan makamları, bu krizi ortadan kaldırmak amacıyla 1956 ve 1957 'de 150 Kürt aileye ve benzer sayıda Süryani Hiristiyan'a da mezhepsel denge için Lübnan vatandaşlığı verdi. Kürtlerin ve diğer birçok grubun da olduğu 30 Haziran 1994'de Cumhurbaşkanı Elias Hrawi, Başbakan Refik Hariri ve İçişleri Bakanı Bishara Merhej arasındaki iki yıl süren görüşmeler sonrasında yaklaşık 130.000 kişiye Lübnan vatandaşlı̆̆ sağlayarak vatandaşlık sorununu çözebildi. ${ }^{42}$ Lübnan anayasası, tüm vatandaşlara eşit haklar garanti ederken, Lübnan kanunları, kadın üzerinde daha fazla kontrol sağlamak için erkeğe yasal olarak ayrıcalık tanımaktadır. Öreğin Lübnanlı bir erkekle evli olan yabancı bir kadına, bir yıllık bir süre sonunda ve isteği üzerine Lübnan vatandaşlığı verilirken, bir yabancı ile evli olan bir Lübnanlı kadına yasaklanmıştır. ${ }^{43}$

\section{Sonuç}

Lübnan'daki Kürtler, tarihsel bir varlık olmaktan ziyade Lübnan ve çevresinde geçici olarak paralı bir askeri varlık olarak bulunmuştur. Zira tarihsel bir varlık olmaları için içtimai, iktisadi ve siyasi olarak kurumsal bir kimliklerin olması gerekmektedir. Ayrıca Lübnan'daki 'Nüfus Sayımı' probleminin günümüzde de devam ediyor olması, Lübnan'daki Kürt nüfus istatistiklerine dair bilgiyi ihtimale, yoruma ve spekülasyonlara açık hale getirmiştir. Kürtler, Lübnan'a göç ettikleri evrede kendilerini topluma entegre etmek için gerekli ekonomik araçlara ve siyasi bağlantılara sahip olamamışlardır. Bu durum da Lübnan'ın kamusal alanı ve toplumsal yapısı ile uyum sorununa neden olmuştur. Lübnan'daki Kürtler, dil, kültür ve tarihi geçmişine ilişkin farklılık göstermektedir. Dilleri, kültürleri ve tarihi geçmişleriyle ilgili olarak içtimai ve iktisadi anlamda bütünleşememiş bir azınlık gibi görünmektedir. Kürtlerin bu durumu, Lübnan sisteminin kurumsal yapısının ve sosyo-politik normlarının bir sonucundan ziyade aile kimliği veya birey açısından bir araç olarak kullanılan eski kabile veya geleneksel uygulamalarını sürdürmelerinden kaynaklanmıştır. Kürtler, Lübnan'da siyasi anlamda Sünni Müslüman kimliği altına alınmıştır. Kürtlerin yoksulluk sınırında veya altında yaşadığını ve okuryazarlık oranlarının düşük olduğu ortaya çıkmıştır. Kürtler, Lübnan toplumunun sosyal katmanları konusunda düşük sosyal işlerle uğraşmaktadır. Dolaysıyla Kürtler, Lübnan sosyolojisinde de önemli bir etki alanına sahip olmamıştır. Kürtler, iyi bir servete ve eğitime sahip olmadıklarından sosyal sınıf olarak alt tabakaya mensup olmuştur. Ancak vatandaşlık almış Kürtler, sosyo-ekonomik durumlarını iyileştirmiştir. Vatandaşlık alan Kürtler, Lübnan sistemine entegre olduğundan ekonomik imkanlardan da yararlanmışlardır. Beyrut'ta vatandaşlığa geçmek, Beyrut seçmeni olarak bir değer anlamına geldiğinden Kürtler açısından da önemli bir

\footnotetext{
41 Lokman İbrahim Meho, agt., s.51.

42 Lokman İbrahim Meho, s.52.

43 Daha fazla bilgi için bkz. Lamia Rustum Shehadeh, agm, s.512.
} 
statü kazandırmıştır.

\section{Kaynakça \\ İngiliz Arşivleri}

Foreign and Commonwealth Office Records (FCO)

FCO, 93/1999.

FCO 93/2421.

\section{Vilâyet Salnâmeleri}

Beyrut Vilâyet Salnâmesi Şimal Kısmı, H. 1333-1336 (M. 1914-1915/1917-1918).

\section{Kaynak Eser ve İncelemeler}

Abdülhadioğlu, Ahmet, "Kadim Arap Kültürünün Midyat Halkının Gündelik Yaşamına Yansımaları”, Uluslararası Midyat Sempozyumu 7 -9 Ekim 2011, s. 789-803.

Avc1, Casim, "Yâkūt El-Hamevî”, TDV İslâm Ansiklopedisi, c.43, (2013), s.288-291.

Bayat, Fazıl, “Trablusşam Eyaleti”, TDV İslâm Ansiklopedisi, c.41, (2012), s.295-296.

Bilge, Yakup, "Turabdin: Süryani Kilise ve Kültürünün Beşiği”, Uluslararası Midyat Sempozyumu 1-9 Ekim 2011, s. 507-529. 2018.

Bora, Tanıl, Cereyanlar Türkiye'de Siyasî İdeolojiler, 6.Baskı, İletişim Yayınları, Aralık

Demirkent, Işın, "Haçlılar”, TDV İslâm Ansiklopedisi, c. 14, 1996, ss. 525-546.

Elısséeff, N., "Hișn al-Akrād”, Encyclopaedia of Islam, Second Edition, Editedby: P. Bearman, Th. Bianquis, C.E. Bosworth, E. vanDonzel, W.P. Heinrichs.

Hourani, Guita G., The Kurds of Lebanon: Socioeconomic Mobility and Political Participation via Naturalization, The Lebanese Emigration Research Center (LERC) Notre Dame UniversityLouaizé (NDU), Lebanon, November 2011.

Jureidini, Ray, "In the Shadows of Family Life: Toward a History of Domestic Service in Lebanon "Journal of Middle East Women's Studies, Vol. 5, No. 3, War and Transnational Arab Families (Fall 2009), pp. 74-101.

Kawtharani Farah Wajih, The Interplay OfClientelism And Ethnic Identity in Pluralist States: The Case of The Kurdish Community In Lebanon, (Department of Social And Behavioral Sciences of The Faculty of Arts And Sciences, American University Of Beirut Unpublished master's thesis), Beirut 2003.

Mcdowall, David, A Modern History of The Kurds, I:B.Tauris, New York 2007.

Meho, Lokman İbrahim, The Dilemma of Social And Political Integration of Ethnoclass Groups Within Pluralistic Societies: The Case of The Kurds In Lebanon, (Political Studies and Public Administration of the Faculty of Arts and Sciences,American University of Beirut Unpublished master's thesis) Beirut, Lebanon 1995.

Milwright, Marcus, "Hịṣn al-Akrād”, Encyclopaedia of Islam, Three, Edited by: Kate Fleet, Gudrun Krämer, Denis Matringe, John Nawas, Everett Rowson. 
Mumcu, Uğur, Kürt-İslam Ayaklanması 1919-1925, 32.bask1, Uğur Mumcu Araştırmac1 Gazetecilik Vakfı Vayınları, Ankara 2018.

Özalper Mehmet, "Bir Muhalefet Partisinin İlgası: Terakkiperver Cumhuriyet Firkası", Anemon Muş Alparslan Üniversitesi Sosyal Bilimler Dergisi, c.2, Muş2014., 117-136,

Özoğlu, Hakan, Osmanlı Devleti ve Kürt Milliyetçiliği, Kitap Yayınevi, İstanbul 2005.

Salibi, Kamal S., "The Sayfās and the eyalet of Tripoli 1579-1640”, Arabica, T. 20, Fasc. 1, Feb. 1973, p.25-52.

Shehadeh, Lamia Rustum, “The Legal Status of Married Women in Lebanon”, International Journal of Middle East Studies, Vol. 30, No. 4 (Nov., 1998), pp. 501 - 519.

Tucker, Jason, Challenging the tyranny of citizenship: statelessness in Lebanon, (Unpublished phd thesis), University of Bath, Sept. 2013.

Vanly, Ismet Chériff,, "The Kurds in Syria and Lebanon", The Kurds A Contemporary Overview, (Ed. Philip G. Kreyenbroek and Stefan Sperl), Routledge, London 1992.

Yâkūt el-Hamevî, Mu'cemü'l-büldân, Dâru's Sadr, Beyrut.

Yeşilmen, Halit, Etno-Dini Kimlik Açıdan Mahallemiler, Artuklu Akademi, 2016/3 (2), 140.

\section{Elektronik Kaynaklar:}

Aboumerhi, Najlaa, "Kurds in Lebanon", https://www.beirutobserver.com/2012/03/kurds-in-lebanon-najlaa-aboumerhi/, (E.T.08.03.2019).

Anderson, Brooke, Kurds endure poverty, grapple with assimilation, The Daily Star, Feb. 09,2012, http://www.dailystar.com.lb/News/Local-News/2012/Feb-09/162690-kurds-endurepoverty-grapple-with-assimilation.ashx\#axzz1lrOIfEZD, (E.T.18.07.2019).

Budak, Bahaeddin, "Mahallemi Lehçesi", http://www.mahallemi.net/2012-07-19-10-4929/187-bahaeddinbudak.html. (E.T.08.03.2019).

Kayıp Kürt kolonileri: Misır, Ürdün, Lübnan, Filistin ve Yemen Kürtleri, http://www.bitlisname.com/2018/07/30/kayip-kurt-kolonileri-misir-urdun-lubnan-filistin-ve-yemen-kurtleri/, (E.T.30.07.2018).

SCALBERT-YÜCEL Clémence and Marie Le Ray, "Knowledge, ideology and power. Deconstructing Kurdish Studies", European Journal of Turkish Studies [Online], 5/2006, URL: http://journals.openedition.org/ejts/777.

Tuttle, Robert, Lebanese Kurds march on Parliament, The Daily Star, Feb. 20, 1999, http:// www.dailystar.com.lb/News/Lebanon-News/1998/Nov-18/34756-jumblatt-stands-with-kurds-instruggle-over-pkk-leader.ashx. (E.T.18.07.2019).

"Jumblatt stands with Kurds in struggle over PKK leader" The Daily Star, Nov. 18, 1998, http://www.dailystar.com.lb/News/Lebanon-News/1998/Nov-18/34756-jumblatt-stands-withkurds-in-struggle-over-pkk-leader.ashx, (E.T.18.07.2019).

Minority Rights Group International, World Directory of Minorities and Indigenous PeoplesLebanon, June 2008. https://www.refworld.org/docid/4954ce52c.html. (E.T.13.07.2019). 


\section{EKLER}

Ek-I

Beyrut Vilayet Salnamesi s.263



Kaynak: Beyrut Vilâyet Salnâmesi, Şimal Kısmı, H. 1333-1336 (M. 1914-1915/1917-1918). 
Ek-II

Lübnanlı Kürtlerin 2010 yılı Beyrut’taki mahallelere göre dağılımı.

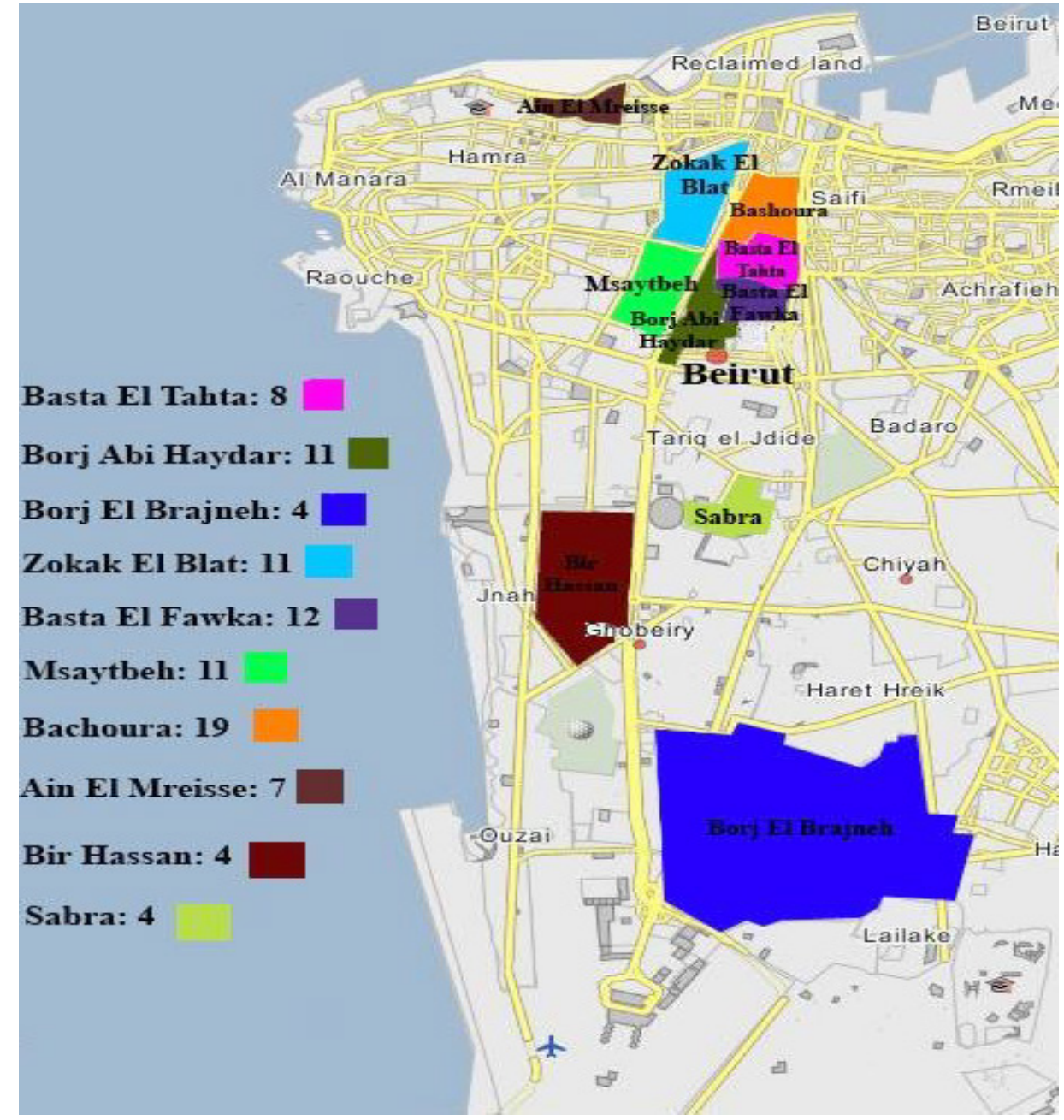

Kaynak: G. Hourani 